\author{
Janina Godłów-Legiędź \\ University of Lodz \\ Faculty of Economics and Sociology \\ Department of Macroeconomics \\ e-mail: janina.legiedz@uni.lodz.pl
}

\title{
The institutional context of rationality
}

\begin{abstract}
In the last three decades, mainstream economics has been influenced by authors associated with new institutional economics and new behavioral economics. The dispute over rationality as an assumption of economic theories is becoming particularly evident and is taking new forms. The aim of this article is to examine the connections between the institutional and behavioral approaches as well as between researchers' ideas as to what rationality is and their beliefs regarding an optimal economic system. It will demonstrate that so-called behavioral and institutional economists have more in common than not. Institutions play a key role in the arguments of behavioural economists, whereas the argument of institutional economists is almost always based on the issue of human cognitive abilities and emotions. What directly links the two trends is the attention given to the rationality of actions that an individual takes as a premise of economic choices and as an assumption of economic theories. Differences in views relate to the understanding of rationality and exist within the framework of behavioral economics itself. At the core of the dispute is the distinction between two concepts of rationality: constructivist and ecological. This distinction serves as a starting point for the second matter discussed in the article. The author argues that the concept of constructivist rationality is related to the vision of the top-down creation of social order, while the proponents of the ecological approach to rationality stress the importance of market institutions. Interestingly, from the perspective of
\end{abstract}


cognitive psychology and the heuristics of Daniel Kahneman, it can be presumed that the convictions of a scholar about the "ideal system" can influence his or her arguments on the essence of human rationality.

Keywords: behavioural economics, institutions, constructivist rationality, ecological rationality, economic order

JEL Classification: B25, B4, P0

\section{Introduction}

In search of fundamental determinants of economic development, some researchers tend to focus on human nature, while others on social institutions. The growing interest in psychology-related behavioral economics may indicate that the economic pendulum is shifting towards human nature and rationality considered from the perspective of the individual. The development of both behavioral economics and new institutional economics may be seen as a manifestation of the crisis in the current economic paradigm - the crisis understood as the critical look at development up to now as well as the search for a new place for economics among the social sciences. In this context, the question is whether the interest in psychology and behavioral economics implies that an institution as an object of economic research fades into the background. In other words: is the behavioral trend in economics replacing the institutional trend in its role of reviving mainstream economics? The article has two objectives: (1) proving that these two trends in economics are not competitive, let alone alternative, and (2) drawing attention to the relationship between the researchers' ideas as to what rationality is and their convictions about the optimal economic system. Pursuing the first objective, the author will seek to demonstrate that institutions perform a major role in the arguments of behavioural economists, whereas the arguments of institutional economists almost always take into account the issue of human cognitive abilities and emotions. What directly links the two trends is the attention given to the rationality of human actions as a premise of economic choices and as an assumption of economic theories. And while differences between the two views exist, they do not result in a psychological-institutional dichotomy. Instead, they are reflected in the adopted concept of rationality. Therefore, at the core of the article, there is a distinction between two concepts of rationality: constructivist and ecological. This distinction serves as a starting point for the second objective of the article. The author argues that the concept of constructivist rationality is related to the vision of the top-down creation of social order, while the proponents of the ecological approach to rationality highlight the importance of market institutions. Interestingly, from the viewpoint of cognitive psychology and the heuristics of Daniel Kahneman, it can be presumed that economists' convictions about the "ideal system" can influence their arguments regarding the essence of human rationality. 


\section{The concept of ecological rationality in behavioral and institutional economics}

The integration of psychological and economic research, which occurs in the development process of behavioral economics, enhances the twofold understanding of rationality. On the one hand, rationality is understood as a property of human actions and thoughts. A person is rational when he or she consciously applies scientific rules, algorithms, internally consistent theories, and makes decisions that are logical, internally consistent and consistent over time. The brain is a habitat of rationality read in this manner. This type of rationality, deriving from Descartes, is sometimes referred to as constructivist rationality, constructivism, or scientism. On the other hand, a concept is developed according to which rationality arises spontaneously, being the creation of not only the conscious and planning mind, but also of intuition and spontaneous processes of adaptation to the environment. This type of rationality is referred to as critical rationality (Friedrich Hayek), bounded rationality (Herbert Simon), adaptive rationality (Gerd Gigerenzer) or ecological rationality (Vernon Smith).

Mainstream economics is strongly related to the concept of constructivist rationality, which determined the methodology and development of economics in the $20^{\text {th }}$ century, and frequently contributed to isolating economic issues from psychological and institutional matters. It can be observed, however, that when these issues, which had thus far been considered foreign to economics, became the subject of more formal analysis, when scholars examining them started using methods based mainly on the abstract deductive reasoning, the door to the mainstream of economics opened up in front of them. This is what happened with new institutional economics and repeats itself in the case of behavioral economics.

Kahneman's research contributes to making economists aware of the three basic characteristics of a human as an economic subject: limited cognitive potential, limited willpower and the complexity of motives for action. ${ }^{1}$ However, the normative model of Kahneman's rationality is consistent with the model dominant in neoclassical economics. Kahneman clearly accepts the neoclassical norms of rational (maximizing) behavior when from the point of view of these norms, he tries to prove that thought processes are characterized by cognitive distortions and that the decisions of individuals are burdened with systematic errors (Altman, 2004, p. 10). Kahneman owes his economic stance to the criticism of conventional economics and its assumptions about the goals, possibilities and methods of making decisions. Yet, describing two systems of human thinking and relating so

\footnotetext{
${ }^{1}$ In fact, economics has been aware of these traits since it emerged as a separate discipline, which is best evidenced by the work of Adam Smith. Nonetheless, it is the economists working on the assumption of a rational economic subject striving to maximize utility who have gained the most considerable influence since the end of the $19^{\text {th }}$ century.
} 
explicitly all cognitive distortions to system 1 , he adopts as the instrumental model of neoclassical economics as a model of rationality. Without a doubt, he prefers system 2 , which is the system based on algorithms, principles and mathematics. ${ }^{2}$

Alternative approaches to rationality are of an ecological character in the sense that they consider human thinking and actions to be rooted in a changing natural and social environment. The essence of the ecological rationality concept lies in the empirical-evolutionary view on the development of human cognitive abilities, the awareness of how significant unconscious thinking processes are and arguing that there is little point in considering the issue of rationality in isolation from the environment in which economic decisions are made. This way of thinking received a response in modern economics owing to Herbert Simon, but its sources can be traced back to the philosophy of the Scottish Enlightenment, which Friedrich Hayek stressed with great passion. ${ }^{3}$

Simon drew attention to the complexity and uncertainty of the environment in which a person makes decisions and to the fact that humans are not omniscient. A person does not have full knowledge of all the circumstances of a given problem, does not know all possible solutions and is not able to predict all potential consequences (1978, p. 356). The decision-making process takes place on a trial and error basis - it is analogous to looking for a way out of a maze (1962, p. 472). Such a process increases the costs, and thus searching for the best solution (maximizing the goal) may prove too expensive and irrational. If we consider the actual decision-making conditions, we will realize that it is rational to look for a satisfactory solution, not the best one.

Simon's concept of rationality puts emphasis on the significance of experience, custom and intuition. Experience becomes human capital, which is activated through the use of custom and intuition. Intuition is a crucial element of human rationality. Intuition is founded on accumulated knowledge and experience. Intuitive solutions appear suddenly, but they appear in a "prepared mind". Simon came to this conclusion while investigating the problems of artificial intelligence (Frantz, 2005, pp. 119-123).

Vernon Smith, who - as Roger Frantz rightly wrote (2013, p. 7)—connects the first and the second generation of behavioural economists, also criticizes the constructivist approach to rationality. Nonetheless, it should be added that the only thing Vernon Smith has in common with Kahneman and the second stage of the behavioral economics development is the time and publicity associated with the

\footnotetext{
${ }^{2}$ Kahneman exposed the differences between systems 1 and 2 of the human mind, deliberately assigning them the role of two actors who make it easier to present cognitive illusions (Kahneman, 2012, pp. 41-43). Critics of the dual system theory point out that it draws a sharp line between intuitive and conscious judgments, which does not find sufficient support on either the theoretical or empirical grounds (Keren \& Schul, 2009, pp. 535-536). The concept of two systems is an essential element that distinguishes the so-called new behavioral economics from its earlier version. The older behavioral economics emphasizes the interpenetration of reasoning and learning processes, which supporters of the two systems theory tell apart (Dzionek-Kozłowska, 2016, p. 123).

${ }^{3}$ Hayek's view on rationality and individualism in the context of disputes over the possibility of creating social order was presented in a lecture delivered in 1945 at the University of Dublin, entitled Individualism: True and False. The lecture was published in the collection Individualism and Economic Order (1972).
} 
2001 Nobel Memorial Prize that they received jointly. Smith's approach to the question of rationality reveals his close similarity to the older generation of behavioral economics and to Friedrich Hayek, who, as Frantz asserts, was previously the one to address almost all of the problems associated with behavioural economics (2013, pp. 1-34). Vernon Smith questions the conclusions drawn from the research program that identifies cognitive biases and distortions. While he acknowledges many discoveries made by cognitive psychologists regarding the nature of cognitive processes, he maintains that it is a mistake to derive the rationality of economic system and market from the rationality of individuals (2013, p. 186). This erroneous view is what connects Kahneman's position with neoclassical economics. Kahneman treats the irrational behaviours of individuals as the source of the irrationality of group behaviours and market processes; neoclassical economics seeks to negate all manifestations of irrationality in the behaviour of individuals so as to prove rationality at the level of an economic system. In both cases, it is assumed that one can assess the rationality of individuals and the rationality of the market by assessing the behaviour of individuals isolated from the social context, which means that rationality is evaluated independently of social institutions. It is exactly the element of thinking about rationality that makes one aware of the relationship between the question of rationality and institutions, and so between the behavioral approach and the institutional one.

Vernon Smith, referring to the legacy of Scottish moral philosophers and Friedrich Hayek, as well as to Herbert Simon, focuses on rationality understood as a "social skill" of creating social order and achieving efficiency, which Douglass North called adaptive efficiency. The idea of ecological rationality is, therefore, connected with the view that social order cannot be planned by one mind, but emerges from the cultural and biological processes of evolution. Ecological rationality is not a trait or product of a single human mind, but an effect of the interaction between the activity of numerous human minds and actions.

Truth is discovered in the form of the intelligence embodied in rules and traditions that have formed, inscrutably, out of the ancient history of human social interactions. This is the antithesis of the anthropocentric belief that if an observed social mechanism is functional, somebody in the unrecorded past must have used reason consciously to create it to serve its perceived intended purposes. (V.L. Smith, 2003, p. 470)

Opposing the idea of human omniscience and the possibility of shaping social reality in accordance with the adopted ideal (the position to which the scholar referred as constructivism), Hayek put forward an argument that the human mind is the product of evolution itself and as such cannot go beyond the previous experience. This could suggest that there is no possibility to perfect institutions. However, it is not the case. Hayek simply sought to demonstrate the difficulties of radical top-down remodeling, but he promoted the idea of bottom-up changes. If a bottom-up and locally implemented innovation brings more damage than benefits, it can be rejected, and the cost of the experiment will not go up too high. And those new ideas that pass the initial tests will be propagated. Individual rea- 
son must be constantly supported by knowledge contained in the institutions that are established through trial and error. As Smith notes (2003), Todd Zywicki offers an interesting outlook on the matter, stating: "reason is good at providing variation, but not selection."

Friedrich Hayek is one of these authors to whom Vernon Smith referred exceptionally often. Smith was fascinated by Hayek's critique of constructivism in the context of psychological and institutional approaches to the problems of knowledge, learning and social order. It should be noted that, to a similar degree and for the same reasons, the work of Hayek also appealed to Douglass North. The notorious institutionalist and historian took a keen interest in the processes of creating knowledge and human perceptions of the world, recognizing them as the basis of an institution, adaptive efficiency and social order. North analyzes the process of learning and shaping beliefs from the perspective of an individual and of the whole human species. Psychology mixes with history and anthropology since learning is a process that takes place not only in the human brain but also in interactions with a changing social environment. This way, North implicitly proposes to replace the rational choice paradigm with the cognition paradigm. In the field of the economic research, the issue of how adequate human aspirations and beliefs are in relation to the social and the technological reality, which change at increasingly faster pace, takes a central place of rational resource allocation.

The "reality" of a political-economic system is never known to anyone, but humans do construct elaborate beliefs about the nature of that "reality"-beliefs that are both a positive model of the way the system works and a normative model of how it should work. (North, 2005, p. 2)

Individuals make choices according to their intentions, and the cost-benefit account lies at the base of these choices. Nevertheless, in order to understand them, it is necessary to explain the belief-shaping process and not the assumptions of the ideal rationality. What is considered rational choice results not so much from individual reflection, but rather from placing the thought process in a broader institutional context (North, 2005, p. 24).

Replacing rationality with beliefs has serious consequences. The assumption of rationality implies that an individual has a "proper" understanding of the reality and conditions of the choice. Beliefs and mental models are concepts that allow an individual to understand and interpret the same decision-making conditions in a variety of ways. By exposing the significance of mental models, North exposes how diverse the objectives of human actions really are. Abandoning the idea of neoclassical rationality and exploring various conditions of shaping beliefs allows us to understand why, from a historical point of view, economic growth was an episodic phenomenon, while human consciousness was and remains not only the source of great creativity that makes human life possible and enriches it, but also the source of prejudice, dogmas, fanaticism, and as a consequence of the Holocaust-prolonged wars and terrorism (North, 2005, p. 167). If development was determined by an increase in the resources of scientific knowledge and tech- 
nology, the future of the human race-North underlines $(2005$, p. 3 ) — would not be put into question. However, due to complex dependencies between consciousness and culture, such factors as religious fundamentalism, ethnic hatred and racist stereotypes are involved and make peaceful development an incidental phenomenon.

North reveals the two-way relationship between the consciousness of an individual and the historical-cultural context. By doing so, he avoids making the onesided interpretation of the historical process, which is typical of the representatives of both individualism and holism. He demonstrates that social processes cannot be explained using a simple scheme of cause-and-effect relationships: from an individual to society or from society to an individual. By tracing throughout history the conscious efforts of human beings to control the natural and social environment, the scholar illustrates to what extent the effects of these efforts depend on the limitations and possibilities contained in the instruments of social communication and cooperation, such as language, customs, moral principles and law. The basis of cognition and consciousness is the genetic architecture of the mind, which, however, leaves many areas undefined, creating more room for environmental adjustments. In this undefined space, culture creates an artifactual structure, through which an individual perceives the world and which can become an object of influence on the path to well-being and peaceful coexistence (North, 2005 , pp. 27-28, 48-52). Hence, North comes to the conclusion that "creating the necessary artifactual structure is an essential goal of economic policy" (2005, p. 700). North's view on institutional change reveals the relationship between economics and the "new thinking" about the evolution of human cognition and speaks for the integration of economics not only with psychology, but also with anthropology, evolutionary biology and neurology. ${ }^{4}$

\section{3. "Anchored" ideas about economic order and rationality}

Concepts of rationality and ideas concerning its determinants play a major role in the discussion on the possibilities of creating a desired social order and an economic system meant to achieve set out goals. Even though conclusions on economic systems are formulated based on the ideas about the rationality of an individual, one may venture the hypothesis that if a scholar is attached to a specific concept of an economic system, he or she may be inclined to search for arguments that support a specific concept of rationality. While the connections between the concepts of rationality and the postulates of an economic system are not of a purely cause-and-effect nature, it is possible to point out examples of interesting dependencies.

\footnotetext{
4 "New thinking" about the evolution of human cognition draws attention to the interaction of cultural, technical and biological evolution and the role of social communication methods. It is founded on the integration of anthropology, archeology, economics, evolutionary biology, neurology, philosophy and psychology. Cf. Heyes, 2012, p. 2091; Frith, 2012, p. 2213.
} 
Friedrich Hayek's doctrine provides a notable example. The economist advocates that the constructivist interpretation of rationality be closely associated with the socialist and the interventionist beliefs. The theory of reason being independent of experience, and the belief in unlimited possibilities of the human mind leads to the conviction that there are unlimited possibilities when it comes to the topdown shaping of social institutions and of the entire socioeconomic system. A belief that civilization is a fully rational construct, in the sense that all its institutions were created with full awareness of their consequences, indicates a program for the future - the desire to consciously create a new social order, with a deep belief that the mind allows humans to choose and create new social institutions that guarantee the achievement of better outcomes than those of spontaneous social processes (Hayek, 1969, pp. 84-85). At the same time, full of determination, Hayek gathered arguments for critical rationalism from the fields of philosophy, psychology and anthropology, based on which he formulated his vision of the market economy. His determination to defend a free market may lead one to believe that a stance on the optimal system sets a certain path of inquiry into rationality. On the other hand, it can be assumed that Hayek's ideological commitment deters other scholars from paying sufficient attention to his ideas, as they are put off by his commitment to defending the free-market social doctrine.

Vernon Smith, who strongly identifies with the position of Hayek and of classical liberals, is an example confirming the connection between the ecological interpretation of rationality and faith in the effectiveness of the market economy. Developing the ecological interpretation of rationality, he considers the cognitive apparatus of an individual in terms of free markets, continuous social interactions and cultural evolution. In Vernon Smith's view, the errors of individuals, which are so strongly emphasized in Kahneman's teachings, occur naturally due to a lack of knowledge and experience. The scholar stresses that the cognitive biases of individuals are corrected in the process of learning and gaining new experiences. Thus, he believes that an individual's decision-making process is generally rational. The challenge Vernon Smith puts in front of science consists in explaining the transformation of individual behaviours into larger social systems of behaviour (Altman, 2004, p. 21). The author seems to ascribe unsatisfactory results in this field to the influence of constructivist rationalism, which makes it difficult for people to accept that prosperity can be achieved in other ways than through conscious cognition, understanding and management. Smith makes a valid point saying that a fault of commonly used economic models stems from the one-sided interpretation of rationality. The fault lies in the fact that instead of being regarded as the processes of learning, market processes are built on the assumption of rationality of an individual isolated from the social context. In his experiments, Vernon Smith argues that, contrary to the conclusions drawn from research grounded in game theory and the fascination with the "prisoner's dilemma" say, coordination mechanisms do operate, as Adam Smith indicates, and that institutions are social instruments used to strengthen and stimulate the rationality of an individual. 
Like the modern psychology of cognitive processes, Smith arrives at the conclusion that human cognitive abilities are developed not based on reason alone, but through social interaction with other people (Hodgson, 2004, p. 413).

This paradigm shift involves a move away from the idea of the mind as an independent rational deliberator, toward a view of the mind as a controller of embodied activity located in a larger system including the body and its social and physical environment. For each individual agent, the material and social context of activity helps to constitute meaning and action. (Hodgson, 2007, pp. 329-330)

Vernon Smith also displays elements of attachment to market philosophy, which can be interpreted in terms of anchoring. Yet, the undeniable worth of the rationality concept that he put forward - and the same is true about Hayek, Simon, Gigerenzer and, in general, all supporters of the ecological, adaptive and evolutionary interpretation - is that it leaves room for learning and thus, rationality is treated as a gradable trait. ${ }^{5}$

\section{Conclusions}

In accordance with the concept of ecological rationality, not only the human mind but also the institutions that emerge in the process of social evolution are the source of right solutions, while progress is achieved through constant learning and making use of the wisdom contained in the institutions. Progress is possible only in conditions of freedom, i.e., without the top-down control, when human reason is developing in symbiosis with institutions. ${ }^{6}$ The emphasis placed on the significance of social context, cultural evolution and institutions shows that the rationality concept of Vernon Smith, as well as of Herbert Simon who represents the older generation of behavioral economics, is closely related to institutional economics. North's concepts illustrate the importance of cognitive psychology from the perspective of institutional development theories. Hayek's doctrine, in which the institutional-evolutionary and the psychological approaches are adopted, is a special and vital link between the older and the younger generation of behavioral economists as well as between the behavioural and the institutional trend. Recognizing the unquestioned contribution to economics by the above-mentioned scholars means that economic research must take into account the psychological and biological as well as institutional, sociological and historical aspects. The distinction between the institutional and the behavioral trend is, to some extent, dictated by our tendency to divide and classify.

\footnotetext{
${ }^{5}$ Gradation is an immanent feature of rationality in the concepts of those who criticize constructivist rationality. On the advantages of treating rationality as a variable, cf. Etzioni, 2011, pp. 277-287.

${ }^{6}$ This concept is expressed in the notion of extended order, introduced by Hayek (2004, pp. 29-36), and the symmetric term of extended brain, used by Carsten Herrmann-Pillath (2009, p. 201).
} 
As one of the areas of human activity, science is not free from the consequences ensuing from the limitations of human rationality either. Researchers and experts are also subject to cognitive distortions. If the stance on an optimal system affects the process of explaining economic mechanisms and the determinants of human rationality, we may see it as an indicator showing that several cognitive heuristics are in operation: the effect of endowment, anchoring, as well as accessibility and emotions. Acknowledging the possibility that these effects can also be present in the process of scientific cognition should be considered, from the point of view of economic methodology, of great value, added by the research program of Kahneman's cognitive psychology. It would be difficult to overstate the significance of a resulting methodological norm: the criticism of own beliefs and research methods.

\section{References}

Altman, M. (2004). The Nobel Prize in behavioral and experimental economics: A contextual and critical appraisal of the contributions of Daniel Kahneman and Vernon Smith. Review of Political Economy, 16(1), 3-41.

Dzionek-Kozłowska, J. (2016). Homo oeconomicus w XXI wieku. Imperializm ekonomii a ekonomia behawioralna. In M. Gorazda, Ł. Hardt, \& T. Kwarciński (Eds.), Metaekonomia. Zagadnienia z filozofii ekonomii (pp. 105-130). Kraków: Copernicus Center Press.

Etzioni, A. (2011). Behavioural economics: Next steps. Journal of Consumer Policy, 34(3), 277-287.

Frantz, R. (2005). Two minds: Intuition and analysis in the history of economic thought. New York, NY: Springer-Verlag.

Frantz, R. (2013). Frederick Hayek's behavioral economics in historical context. In R. Frantz, \& R. Leeson (Eds.), Hayek and behavioral economics (pp. 1-34). New York, NY: Palgrave Macmillan.

Frith, Ch. D. (2012). The role of metacognition in human social interactions. Philosophical Transactions of the Royal Society B, 367, 2213-2223.

Hayek, F. (1969). Studies in philosophy, politics and economics. New York, NY: Simon and Schuster.

Hayek, F. (1972). Individualism and economic order. Chicago: A Gateway Edition.

Hayek, F. (2004). Zgubna pycha rozumu. O błędach socjalizmu. Kraków: Arcana.

Herrmann-Pillath, C. (2009). Elements of Neo-Veblenian theory of the individual. Journal of Economic Issues, 41(1), 189-214.

Heyes, C. (2012). New thinking: The evolution of human cognition. Philosophical Transactions of the Royal Society B, 367, 2091-2096.

Hodgson, G. M. (2004). The evolution of institutional economics. Agency, structure and Darwinism in American institutionalism. London, New York, NY: Routledge.

Hodgson, G. M. (2007). The revival of Veblenian institutional economics. Journal of Economic Issues, 41(2), 324-340. 
Kahneman, D. (2012). Pułapki myślenia. O myśleniu szybkim i wolnym (P. Szymaczak, Trans.). Poznań: Media Rodzina.

Keren, G., \& Schul, Y. (2009). Two is not always better than one. A critical evaluation of two-system theories. Perspectives on Psychological Sciences, 4(6), 533-550.

North, D. (2005). Understanding the process of economic changes. Princeton and Oxford: Princeton University Press.

Simon, H. A. (1962). Architecture of complexity. Proceedings of the American Philosophical Society, 106(6), 467-482.

Simon, H. A. (1978). Rational decision-making in business organizations. Nobel Memorial lecture. https://www.nobelprize.org/prizes/economics/1978/si-mon/lecture/

Smith, V. L. (2003). Constructivist and ecological rationality in economics. American Economic Review, 53(3), 465-508.

Smith, V. L. (2013). Racjonalność w ekonomii. Warszawa: Wolters Kluwer. 